\title{
The Relationship between the Consumption of Different Types of Alcoholic Beverages and Household Income Inequality
}

\author{
GAVUROVÁ, B. ${ }^{1}$, OLÁH, J. ${ }^{2}$, RIGELSKÝ, M. ${ }^{3}$, IVANKOVÁ, V. ${ }^{4}$
}

1 | Tomas Bata University in Zlín, Faculty of Management and Economics, Center for Applied Economic Research, Zlín, Czech Republic

2 | University of Debrecen, Faculty of Economics and Business,

Debrecen, Hungary

3 | University of Prešov, Faculty of Management, Department of Marketing and International Trade, Prešov, Slovakia

$4 \mid$ University of Prešov, Faculty of Management, Department of Economics and Economy, Prešov, Slovakia
Citation | Gavurová, B., Oláh, J., Rigelský, M., Ivanková, V. (2020). The Relation between Consumption of Different Types of Alcoholic Beverages and Household Income Inequality. Adiktologie, 20(3-4), 97-104;

doi 10.35198/01-2020-001-0005
BACKGROUND: The relationship between the consumption of alcoholic beverages and the economic outputs of countries is generally perceived negatively. Recent studies suggest that there is a difference in the effect of different types of alcohol on economic outputs. AIMS: The objective of the present study was to evaluate the relations between alcohol consumption and household income inequality in OECD countries, with a primary focus on selected types of alcoholic beverages. METHODS: In order to achieve this objective, a non-parametric analysis of relationships (Spearman $\rho$ ) and a regression analysis (Instrumental Variables Estimator - Two-Stage Least Squares Regression Analysis) were used. SAMPLE: The countries of the OECD were included in the analyses. The analytical focus was on three dominant types of alcoholic beverages: beer, wine, spirits. Alcohol consumption was expressed in litres of pure alcohol per person over the age of 15 in each country. RESULTS: In OECD countries, beer is the most preferred alcoholic beverage, followed by wine, and spirits are the least preferred. The consumption of beer and wine was significantly related to the Gini coefficient. Thus, an increase in the consumption of beer or wine can be associated with a decrease in the Gini coefficient. In terms of the effects of individual alcoholic beverages on inequality in household income, wine was evaluated most positively, as its increased consumption can lead to a reduction in household income inequality. Spirits had the opposite effect; i.e. increased consumption may increase household income inequality. CONCLUSIONS: Prevention and education should focus on reducing the consumption of spirits, and fiscal interventions such as taxes can also be an effective solution. Alcohol consumption is a cultural aspect that is difficult to eliminate. Therefore, it would be more beneficial to replace spirits with wine.

\section{Keywords | Alcohol Risk - Gini - Beer - Wine - Spirits - Household Income Inequality - OECD}

Grant affiliation | This research was supported by the Internal Grant Agency of FaME Tomas Bata University in Zlín: RV0/2020: “Economic quantification of marketing processes that focus on value increase for a patient in a process of system creation to measure and control efficiency in health facilities in the Czech Republic". 


\section{INTRODUCTION AND THEORETICAL BACKGROUND}

Inequalities are part of the life of every society; people differ in many ways and the same is true for social groups, especially in terms of income. The OECD (2020) defined income as household disposable income in a particular year. It includes earnings, self-employment and capital income, and public cash transfers. Simultaneously, income taxes and social security contributions paid by households are deducted. The income of the household is attributed to each of its members, with an adjustment to reflect differences in needs for households of different sizes.

In general, the term "income inequality" generally refers to the distribution of income among the population of the economy. The widening income gap raises concerns about the sustainability of growth, as well as concerns about social cohesion, and this is the reason why many countries and their public policies are focused on addressing and overcoming this problem (EC, 2017). Income inequality can be measured using various indicators (S80/S20, P90/P10, the Palma ratio), but one of the most commonly used international measurement tools is the Gini coefficient of income. This coefficient is based on the comparison of cumulative proportions of the population against cumulative proportions of the income they receive. The Gini coefficient ranges from 0 to 1 , with 0 representing perfect equality in the distribution of income across the country's population and 1 representing absolute inequality, reflecting a situation in which one person has all the income in the population of a given country (Karriker-Jaffe, 2013; OECD, 2020). From this it is possible to understand that the lower the value of the coefficient, the better the result for the country; thus, the country is closer to income equality.

Despite the dramatic reduction in worldwide income inequality between 2000 and 2010, this problem is still very serious and very sensitive at both the social and political level (Hong et al., 2020). The importance of this issue is underlined by the fact that income inequality is a major factor in people's health and well-being (Pickett \& Wilkinson, 2015) and countries' economic growth (Lee \& Son, 2016). In the European Union, high-income countries are known to have lower income inequalities, as well as higher social security compared to low-income countries, with the social-democratic aspect playing a key role in this regard (Kranzinger, 2020). Overall, income inequality is the result of low income growth in poorer households (EC, 2017). According to Furceri and Ostry (2019), the main determinants of inequality are unemployment, globalization, and technological change, but also demography and the level of development. Hovhannisyan et al. (2019) also examined the determinants of income inequality and revealed that education is negatively and significantly associated with income inequality. To these findings can be added the findings of Tridico (2018), who, in this context, emphasized financialization, labour flexibility, trade unions, and the welfare state.
From the findings, it is clear that income inequality is analysed from different perspectives. The relation between income inequality and health is also a much-discussed topic (Subramanian \& Kawachi, 2004), but in international studies, the relation between patterns of health behaviour and income inequality is rarely considered. The purpose of this study, which focuses on the relation between alcohol consumption and household income inequality, is to fill this gap.

Matthew and Brodersen (2018) confirmed significant relationships between income inequality and several health outcomes, such as heavy drinking, obesity, diabetes, heart diseases, and physical and mental health problems. The authors also emphasized that the effect on low-income people is slightly smaller compared to high-income people. With a focus on alcohol, evidence has shown that income inequality plays an important role in alcohol consumption (Galea et al., 2007), alcohol-related emergency department visits (Reilly et al., 2019), and alcohol-related hospitalizations and alcohol-related deaths (Dietze et al., 2009). This is consistent with the findings revealed by Cutright et al. (2011), who confirmed that income inequality is a very significant predictor of alcohol consumption. Simultaneously, Elgar et al. (2005) found the contextual effect of income inequality on the use of alcohol, and even in this case, it was confirmed that alcohol consumption was higher in higher-income countries. Karriker-Jaffe (2013) found that more intense heavy drinking can be associated with a decrease in income inequality represented by the Gini coefficient. In light drinking, the significance of the association was not confirmed. Looking closely at the authors' results in the classification of race, the Black-White poverty ratio showed a significant positive association rate for both light and heavy drinking, in contrast to the Hispanic-White poverty ratio model, in which the positive significance of the association was found only in light drinking.

Of course, each country is characterized by differences in culture, history, and social perceptions, all of which can be reflected in patterns of behaviour in relation to alcohol consumption. This fact is demonstrated by the OECD report (OECD, 2019a), which shows differences in alcohol consumption between countries from 2007 to 2017, with the countries with the highest alcohol consumption (ranging from 11.6 to 12.3 of litres of pure alcohol per person per year) being led by Lithuania, followed by Austria, France, and the Czech Republic. These countries reported worse results than the OECD average, i.e. 8.9 litres of pure alcohol per person per year. By contrast, Turkey (1.4 litres), Israel (2.6 litres), and Mexico (4.4 litres) reported the lowest alcohol consumption among OECD countries. With a focus on alcoholic beverages, Bentzen and Smith (2018) divided 21 OECD countries into individual categories on the basis of their alcohol preferences. The beer-oriented category consisted of countries such as Australia, Austria, Belgium, Denmark, Germany, Ireland, the Netherlands, New Zealand, the United Kingdom, and the United States. The wine-oriented category was represented by France, Greece, Italy, Portugal, Spain, and Switzerland, and the spirits-oriented category 
included countries such as Finland, Japan, Norway, and Sweden. The authors also emphasized that alcohol consumption patterns may be affected by income; simultaneously, the structural composition of alcohol consumption in these countries has converged over time. Devaux and Sassi (2015) consider socio-economic status and education as factors in alcohol-related behavioural patterns, but these authors also pointed to the opposite view, which shows that patterns and levels of alcohol consumption influence aspects of the labour market. The authors found that higher levels of alcohol consumption were associated with lower job opportunities, wage losses, and lower productivity. On the other hand, in the case of light and moderate levels of alcohol consumption, positive outcomes were observed in terms of the labour market. It is this fact that can contribute to the creation of inequality in household incomes.

On the basis of these findings, it is important to realize that alcohol consumption can lead to higher health risks of serious diseases (McClure et al., 2013; Liangpunsakul et al., 2016; Roerecke et al., 2019; Scherubl, 2019; Klein et al., 2020), as well as death (Rehm and Shield, 2013). At this point, it should be highlighted that different types of alcoholic beverages have different effects on health (Razvodovsky, 2010). According to Kerr et al. (2000) and Coder et al. (2009), consumers of spirits are exposed to the greatest health risk. On the other hand, Sluik et al. (2017) revealed that wine consumption may be associated with a lower risk of diabetes. The beneficial health effects of wine consumption have been confirmed by several other authors (Arranz et al., 2012), while Gronbaek et al. (2000) confirmed this fact in mortality from all causes, coronary heart disease, and cancer. Although O'Keefe et al. (2014) also confirmed that a low to moderate intake of red wine is associated with the strongest reduction in adverse cardiovascular outcomes, the authors still consider excessive alcohol consumption to be the leading risk factor for premature death, especially in men. In any case, alcohol consumption and alcohol addiction are considered to be a considerable health burden (Pruckner et al., 2019). Thus, the findings that suggest that increased alcohol consumption is associated with household income inequality highlight the importance of this issue. On the other hand, there are no studies examining the effect of alcohol consumption on income inequality. Despite being an interesting idea, it still remains unanswered. It is therefore appropriate to examine this relation on each side and also to focus on the different types of alcoholic beverages in this issue.

\section{METHODOLOGY}

Many policies aim to reduce inequalities in many areas of the population's life. Inequalities that are often discussed in political and public life include income inequality. Household income inequality can be caused by several aspects in specific areas, and one of these areas with a more intensive effect can be health. A healthy individual is more productive compared to an individual with a disease; at the same time, higher income may be associated with higher produc- tivity. Alcohol and its individual types have demonstrable effects on health; thus, the existence of a significant relation between alcohol consumption and household income inequality can be expected.

On the basis of the facts mentioned in the previous section, the objective of the present study was to evaluate the relations between alcohol consumption and household income inequality in OECD countries, with a primary focus on selected types of alcoholic beverages. This objective was achieved by several analytical processes; in the first step a descriptive analysis was used in order to provide a more detailed picture of the variables that were analysed. This was followed by an analysis of relationships in order to prove and evaluate the significance of the relations between the consumption of individual types of alcoholic beverages and inequality in household income. The conclusion of the analytical processes in this study was devoted to the application of regression analysis, which verified the statistical significance of the effects of the consumption of individual types of alcohol on the change in the mentioned inequality.

The data was obtained from two available databases, with the World Health Organization - Global Health Observatory data repository (GHO, 2019) providing variables related to alcohol consumption (in litres of pure alcohol per person older than 15 years) and the Organization for Economic Co-operation and Development (OECD, 2019b) providing all the other variables, namely the Gini coefficient (Gini), life expectancy at birth (LE), and chronic liver diseases and cirrhosis (K70s). The analyses included three main types of alcoholic beverages: beer (barley beer 5\%), wine (grape wine $12 \%$, grape must $9 \%$, vermouth 16\%), and spirits (distilled spirits 40\%, spirit-like 30\%). The Gini coefficient (Gini) was also included in the analyses; it provides information on the degree of household income inequality in the range from 0 to 1 ( 0 represents absolute equality and 1 represents absolute inequality in household income). Life expectancy at birth (LE) is a health variable expressing the average life expectancy in countries. The last health variable, chronic liver diseases and cirrhosis (K70s), expresses the diagnosis group of diseases caused by excessive alcohol consumption. The data that was analysed was collected for the period from 2012 to 2017 and all OECD countries were included in the analytical processes (36 countries in 2019).

The above-mentioned objective was achieved by several successive analytical processes, which began with the application of descriptive analysis in order to present in more detail the variables that were analysed. This was followed by an analysis of relationships (Spearman's $\rho$ ). The choice of the correct correlation method was supported by the result of the normality test, which was performed using the Royston multivariate normality test. The conclusion of analytical processes provides the results of regression analysis. Prior to the application of the regression analysis, the presence of outliers was verified by the Bonferroni test, and the presence of significant heteroscedasticity (non-constant variability of residues) was verified by the Breusch-Pagan test. At the same time, a possible problem of endogenei- 
ty was assumed when analysing the effect of alcohol consumption on household income inequality. This was solved using the method of instrumental variables (IV), i.e. the Two-Stage Least Squares (2SLS) regression analysis, while the instrumental variables consisted of LE and K70s.

The programming language R v. 4.0.1 (RStudio, Inc., Boston, MA, USA) (nickname: See Things Now) was used for analysis in the R Studio environment.

\section{RESULT}

This section is devoted to the analytical procedures that lead to the achievement of the main objective. The procedures consist of the use of three main analyses, according to which it is possible to understand the individual parts of the whole analytical process. Thus, the first part is represented by the descriptive analysis, the second part is devoted to the analysis of relationships, and the third and last part is represented by the analysis of effects, as stated in the methodological section.

\begin{tabular}{lcccccc}
\hline Statistic & Beer & Wine & Spirits & Gini & LE & K70s \\
\hline $\mathrm{n}$ & 216 & 216 & 216 & 183 & 215 & 195 \\
\hline Mean & 3.72 & 2.76 & 2.13 & 0.31 & 80.37 & 12.05 \\
\hline Std. Dev. & 1.44 & 1.67 & 1.42 & 0.05 & 2.61 & 7.84 \\
\hline Min & 0.79 & 0.07 & 0.12 & 0.22 & 73.90 & 2.40 \\
\hline Pct|(25) & 2.64 & 1.63 & 1.18 & 0.27 & 78.70 & 6.15 \\
\hline Median & 3.76 & 2.85 & 1.76 & 0.30 & 81.30 & 10.40 \\
\hline Pct|(75) & 4.59 & 3.79 & 2.55 & 0.34 & 82.20 & 15.80 \\
\hline Max & 6.93 & 7.33 & 7.47 & 0.47 & 84.20 & 39.00 \\
\hline
\end{tabular}

Table 1 | Descriptive analysis

\begin{tabular}{lccc}
\hline Relationship & Royston H & Spearman's $\rho$ & p-value $(\rho)$ \\
\hline Beer $\times$ Gini & $29.00^{\dagger}$ & -0.2667 & $2.62 \times 10^{-4}$ \\
\hline Wine $\times$ Gini & $33.30^{\dagger}$ & -0.3635 & $4.23 \times 10^{-7}$ \\
\hline Spirits $\times$ Gini & $66.47^{\dagger}$ & 0.1062 & $1.53 \times 10^{-1}$ \\
\hline
\end{tabular}

Table 2 | Relationship analysis

Note: $\uparrow=p$-value $<0.001$

The first row of Table 1 indicates the number of observations. The Gini coefficient represents the variable with the most missing observations and that is why this variable has the lowest number $(\mathrm{n}=183)$. With a focus on individual types of alcoholic beverages and their consumption in OECD countries, the highest consumption (in litres of pure alcohol per person older than 15 years) can be seen in beer (mean = 3.72 ; median $=3.76$ ), followed by wine $($ mean $=2.76$; median $=2.85$ ), and finally, the lowest consumption was found in spirits (mean =2.13; median =1.76). In OECD countries, the Gini coefficient showed a relatively acceptable level during the period that was analysed $($ mean $=0.31$; median $=0.30$ )
Regarding the variables that indicate the health status of the population in the countries that were analysed during the period from 2012 to 2015, the average life expectancy (LE) was 80.37 years and the diagnosis group of alcoholrelated diseases (K70s) showed an average of 12 deaths per 100,000 members of the population per year.

The evaluation of relationships plays a key role in understanding the relations between alcohol consumption and household income inequality as represented by the Gini coefficient. Table 2 provides the results of the relationship analysis, which pointed to the multivariate normality and the strength of relationships. On the basis of the Royston test, significant deviations from the normal distribution in all the relations that were evaluated can be confirmed; therefore, a non-parametric Spearman correlation coefficient $\rho$ was chosen to evaluate the relations between the consumption of individual types of alcoholic beverages and the Gini coefficient. As can be seen from the results in Table 2, statistical significance was not found only in the relation between spirits and Gini ( $\mathrm{p}$-value $=0.153$ ) The relation between beer and Gini showed a negative low-to-moderate strength of relationship $(\rho=-0.2667$; $\mathrm{p}$-value $<0.001)$. A similar result can be seen in the relation between wine and Gini, in which a moderate-to-substantial negative relationship was found $(\rho=-0.3635$; $\mathrm{p}$-value $<0.001$ ). These results can be considered positive, as an increase in the consumption of beer or wine can be associated with a decrease in the Gini coefficient, and thus with an increase in income equality. This result is very interesting, as it points to the fact that, in terms of the Gini coefficient, positive outputs resulting from the increased consumption of beer and wine predominate.

The results of the regression analysis, which points to the significance of the effects of the consumption of beer, wine, and spirits on household income inequality, can contribute significantly to the present issue. Thus, three models were created, with the first model (BEERm) evaluating the significance of the effect of beer consumption on the Gini coefficient, the second model (WINEm) evaluating the significance of the effect of wine consumption on the Gini coefficient, and the last model (SPIRITSm) evaluating the effect of the consumption of spirits on the Gini coefficient. For greater reliability, tests for the presence of outliers and tests for the constant variability of residues were applied. The problem of endogeneity may arise when assessing the effects of alcohol consumption on household income inequality. This problem was solved by the application of the Instrumental Variables Estimator (IV), i.e. the Two-Stage Least Squares (2SLS) regression analysis. The instrumental variables consisted of LE and K70s.

\begin{tabular}{lccc}
\hline Statistic & BEERm & WINEm & SPIRITSm \\
\hline OLS & $5.69^{* *}$ & $4.61^{* *}$ & $5.69^{* *}$ \\
\hline IV & 0.93 & $4.69^{* *}$ & $7.66^{* * *}$ \\
\hline
\end{tabular}

Table 3 | Homoscedasticity assumption (Breusch-Pagan test) Note: ${ }^{* *}=p$-value $<0.05 ;{ }^{* *}=p$-value $<0.01$ 


\begin{tabular}{lccc}
\hline Statistic & OLS & IV (LE + K70s) & IV (LE + K70s + X^2) \\
\hline BEERm & $-0.01001^{\dagger}$ & 0.01373 & $-0.01057^{\dagger}$ \\
\hline Beer & $0.34919^{\dagger}$ & $0.25932^{\dagger}$ & $0.35247^{\dagger}$ \\
\hline Constant & $\mathrm{NA}$ & $14.589^{\dagger}$ & $662.058^{\dagger}$ \\
\hline Weak instruments & $\mathrm{NA}$ & $11.105^{* *}$ & 1.695 \\
\hline Wu-Hausman & & & $-0.00893^{\dagger}$ \\
\hline WINEm & $-0.01093^{\dagger}$ & $0.33724^{\dagger}$ \\
\hline Wine & $0.34244^{\dagger}$ & $187.232^{\dagger}$ \\
\hline Constant & $\mathrm{NA}$ & $-0.02124^{\dagger}$ & $20.819^{\dagger}$ \\
\hline Weak instruments & $\mathrm{NA}$ & $26.655^{\dagger}$ & $11.247^{\dagger}$ \\
\hline Wu-Hausman & & $0.00523^{* *}$ \\
\hline SPIRITSm & 0.00267 & $0.30072^{\dagger}$ & $173.9^{\dagger}$ \\
\hline Spirits & $0.30541^{\dagger}$ & $0.27425^{\dagger}$ & $8.39^{* *}$ \\
\hline Constant & $\mathrm{NA}$ & $20.55^{\dagger}$ & $12.02^{\dagger}$ \\
\hline Weak instruments & $\mathrm{NA}$ & & \\
\hline Wu-Hausman & &
\end{tabular}

Table 4 | Regression analysis

Note: ${ }^{* *}=$ p-value $<0.05 ;{ }^{* *}=$ p-value $<0.01 ; \dagger=p$-value $<0.001$

Table 3 shows the results of testing for the presence of significant heteroscedasticity. As can be seen, heteroscedasticity occurred in most cases ( $\mathrm{p}$-value $<0.05)$. In these cases, a robust estimate was selected for estimation (White, 1980, 1982). The presence of significant outliers was also tested and no significant outliers were confirmed by the Bonferroni outlier test.

Table 4 provides the results of the regression analysis, which can be considered the most significant output of the whole analytical process with respect to the objective of this study. This table shows the outputs of three models (BEERm, WINEm, SPIRITm) and three variants for each model (OLS; IV (LE + K70s); IV (LE + K70s + X^2)). The OLS variant represents the Ordinary Least Squares estimation method; the IV (LE + K70s) variant represents the 2SLS estimation method, which includes the life expectancy indicator (LE) and the diagnosis group of chronic liver diseases and cirrhosis (K70s) as instrumental variables. The third and last variant (IV $\left.\left(\mathrm{LE}+\mathrm{K} 70 \mathrm{~s}+\mathrm{X}^{\wedge} 2\right)\right)$ also contains, in addition to the previous instrumental variables (LE, K70s), another instrumental variable, i.e. the square of $\mathrm{X}$ (in the case of the BEERm model it is Beer^2; in the case of the WINEm model it is Wine ${ }^{\wedge} 2$; in the case of the SPIRITSm model it is Spirits^${ }^{\wedge} 2$ ). In addition to the coefficients and their statistical significance, the table also shows the results of testing the assumptions of the IV 2SLS regression analysis (Weak instruments, Wu-Hausman). In all the cases that were tested, the value of Weak instruments acquired outputs with asymptotic significance of less than 0.001. Thus, it is possible to confirm the sufficient strength of the chosen instruments in all cases. The result of the Wu-Hausman test of model consistency indicates that endogeneity was not a significant problem in the last variant of the BEERm model (BEERm IV (LE + K70s + X^2) = 1.695). In all the other cases that were tested, it is possible to identify the results of the Wu-Hausman test with an asymptotic significance less than 0.01; therefore, it is possible to speak of the endogeneity problem, which supports the justification of the application of the 2SLS method.

The BEERm model showed significant effects of beer consumption on the Gini coefficient in the first variant $(\beta=-0.01001 ; p$-value $<0.001)$, as well as in the last variant $(\beta=-0.01057 ; p$-value $<0.001)$. In the second variant (IV (LE + K70s)), no significance of the coefficient was found $(\beta=0.01373)$. As follows from the testing of the assumptions, it is appropriate to take into account the result of the IV (LE + K7Os) variant, which considers the effect of beer consumption to be non-significant. Thus, the effect of beer consumption can be considered non-significant rather than significant. The WINEm model is relatively unambiguous, as all variants of this model acquired negative and statistically significant $\beta$ coefficients. Therefore, it can be concluded that the increased consumption of wine may be reflected in a reduction in the Gini coefficient. All three variants of the SPIRITSm model proved to be statistically significant, with the $\beta$ coefficients acquiring positive values. Thus, in the case of an increase in the consumption of spirits, it is possible to expect an increase in the Gini coefficient, i.e. an increase in household income inequality. This result can be considered negative compared to the result of wine consumption.

\section{DISCUSSION AND CONCLUSION}

Alcohol consumption is generally considered to be a major health risk factor (Rehm \& Shield, 2013; Pruckner et al., 2019). Many studies have confirmed the negative health effects of alcohol consumption (McClure et al., 2013; Liangpunsakul et al., 2016; Roerecke et al., 2019; Klein et al., 2020), but it is necessary to take into account the different types of alcoholic beverages and their effects on health. Spirits are considered to be the riskiest (Kerr et al., 2000; Coder et al., 2009; Razvodovsky, 2010); simultaneously, it is possible 
to talk about the positive effects of wine (Gronbaek et al., 2000; Arranz et al., 2012; Sluik et al., 2017). Different types of alcohol pose different risks to the consumer him/herself as well as to society as a whole. Therefore, it is possible to observe the effects of alcohol consumption in the economic life of the country. National and transnational policies emphasize the need to reduce not only health inequalities but also socio-economic inequalities. One of the basic and very important economic indicators of inequality is household income. This study shows that policy makers should focus on alcohol consumption and different types of alcoholic beverages in order to reduce these inequalities.

On the basis of the above-mentioned facts, the objective of the present study was to evaluate the relations between alcohol consumption and household income inequality in OECD countries, with a primary focus on selected types of alcoholic beverages. This objective was achieved by several analytical processes, with descriptive analysis being used in the first step, followed by the analysis of relationships. The last step of the analytical processes was devoted to regression analysis, which pointed out the statistical significance of the effects of alcohol consumption on household income inequality.

The application of the descriptive analysis revealed the fact that the most preferred alcoholic beverage in OECD countries during the period that was analysed was beer, with an average annual consumption of 3.72 litres (of pure alcohol) per person older than 15 years. The consumption of individual types of alcohol also showed that wine is the second most preferred beverage and the lowest consumption was found in the case of spirits, with an average of 2.13 litres (in pure alcohol) per person per year. These findings can be compared with the findings of Bentzen and Smith (2018), who divided OECD countries into wine-oriented, beeroriented, and spirits-oriented countries. The Gini coefficient was approximately 0.30 , which can be assessed positively, as 0 represents absolute equality and 1 represents absolute inequality in household income.

There are many studies that have addressed income inequality and alcohol-related indicators, such as alcohol consumption, alcohol-related emergency department visits, alcohol-related hospitalizations, and alcohol-related deaths (Galea et al., 2007; Dietze et al., 2009; Reilly et al., 2019). On the other hand, the effect of the consumption of individual alcoholic beverages on income inequality remains unknown. The presented study fills this gap in the research and the findings outlined below provide a clear picture of this issue. The analysis of relationships was the second step in the processes fulfilling the objective of the present study. The statistical significance of the relationship between the consumption of individual types of alcoholic beverages and the inequality in household income represented by the Gini coefficient was found in beer and wine. In both cases, a negative coefficient was identified, indicating that increased beer and wine consumption may be associated with a lower value of the Gini coefficient. This finding can be considered positive. From an economic point of view, alcohol consump- tion can be perceived in terms of two main aspects, namely income (tax revenue) and expenditure (the costs of treating alcohol-related diseases, production losses resulting from premature mortality linked to alcohol). In terms of the Gini coefficient, it is possible to consider the fact that the positive aspect of alcohol consumption outweighs the negative aspect. The application of regression analysis showed slightly different results from the analysis of relationships. The effects of beer consumption on household income inequalities were inconsistent, but a non-significant effect was preferred. On the other hand, the effects of wine consumption were clear. In this case, the effects of wine consumption on household income inequality can be seen in a positive context, as its increased consumption may lead to a reduction in the Gini coefficient, indicating a reduction in household income inequality. The opposite situation was found in the case of spirits, and therefore, an increase in the consumption of spirits may lead to an increase in household income inequality. The findings of this study complement the findings of many authors who have shown that alcohol consumption is associated with income inequality (Elgar et al., 2005; Galea et al., 2007; Cutright et al., 2011; Karriker-Jaffe, 2013). Their results showed that income inequality can have an effect on alcohol consumption, but our results proved the opposite relation and confirmed the effect of alcohol consumption on income inequality in terms of classification according to individual alcoholic beverages. Our results extend the findings of Devaux and Sassi (2015), who revealed that higher levels of alcohol consumption were associated with lower job opportunities, wage losses, and lower productivity, and these aspects can lead to income inequality. These findings may encourage further research in this area.

This study shows that the effects of alcohol can be observed not only in the health of the individual, but also in the socio-economic area of life in the country. Therefore, policy makers should focus on the issue of alcohol consumption. The negative effects of alcohol consumption, but especially excessive alcohol consumption, are well known and often discussed. This is a very risky pattern of behaviour, as evidenced by the fact that alcohol consumers suffer from health problems and, last but not least, there is a threat of addiction. Nevertheless, alcohol consumption is still common and frequent in society. It seems that alcohol consumption cannot be eliminated or reduced in society, as cultural and social aspects play an important role. The negative effects of spirits should also be emphasized. On the basis of these facts, the replacement of spirits with wine can be beneficial in many respects. From an economic point of view, increasing the tax on spirits can be an effective solution, as taxes are a powerful tool for reducing alcohol consumption, which can also translate into a reduction in alcohol-related mortality and an increase in government revenue (Sornpaisarn et al., 2016; Chaloupka et al., 2019; Vandenberg et al., 2019). State measures and reforms, interventions, investment in human capital, and a well-designed social system are also needed. As the evidence shows, the prevention of excessive alcohol consumption among the population should also be implemented in social life (Castillo-Manzano et al., 2017; 
Andre et al., 2019). Last but not least, the effectiveness of interventions plays an important role in achieving positive outcomes (Stigler et al., 2011). Health education, especially the Unplugged programme in schools, appears to be the prevention project that shows the best evidence of effectiveness in European studies (Agabio et al., 2015).

This study has strengths and weaknesses. Among the strengths is the fact that the assumption arising from the main objective has been reliably proven and verified in a relatively culturally diversified sample of countries. On the other hand, limitations include the fact that it is very difficult to achieve a full causal relationship, sometimes completely impossible, and therefore, methods are used that increase the relevance of causality. At the same time, a very common problem is endogeneity, which was taken into account in the analyses using the Instrumental Variables Estimator. Overall, the findings are considered relevant. Future research will focus mainly on assessing the relations between alcohol consumption and other commonly used economic outputs. A more specific focus on alcohol consumers is also planned, i.e. future research will cover the economic outputs of countries and the health of the population in terms of alcohol consumption.
Authors' contributions: Conceptualisation: Beáta Gavurová; Data curation: Beáta Gavurová and Judit Oláh; Methodology: Martin Rigelský and Viera Ivanková; Formal analysis: Martin Rigelský and Viera Ivanková; Results: Viera Ivanková; Visualisation: Beáta Gavurová; Final edition: Beáta Gavurová, Judit Oláh and Martin Rigelský. All authors have read and agreed to the published version of the manuscript.
Declaration of interest: Authors declare that they do not have any competing financial, professional, or personal interests from other parties.

\section{REFERENCES}

Agabio, R., Trincas, G., Floris, F., Mura, G., Sancassiani, F., \& Angermeyer, M. C. (2015). A systematic review of school-based alcohol and other drug prevention programs. Clinical Practice \& Epidemiology in Mental Health, 11, 102-112. http://doi.org/10.2174/1745017901511010102

Andre, C., Candido, A., Carreira, T., Santiago, C., Cruz, 0., \& Amendoeira, J. (2019). Prevention of alcohol consumption among young people: a contribution to health literacy. European Journal of Public Health, 29. http://doi.org/10.1093/eurpub/ckz094.001

Arranz, S., Chiva-Blanch, G., Valderas-Martinez, P., Medina-Remon, A., Lamuela-Raventos, R. M., \& Estruch, R. (2012). Wine, beer, alcohol and polyphenols on cardiovascular disease and cancer. Nutrients, 4(7), 759-781. http://doi.org/10.3390/nu4070759

Bentzen, J., \& Smith, V. (2018). Structural changes in the consumption of beer, wine and spirits in OECD countries from 1961 to 2014. Beverages, 4(1), 8. http://doi.org/10.3390/beverages4010008

Castillo-Manzano, J. I., Castro-Nuno, M., Fageda, X., \& Lopez-Valpuesta, L. (2017). An assessment of the effects of alcohol consumption and prevention policies on traffic fatality rates in the enlarged EU. Time for zero alcohol tolerance? Transportation Research Part F-Traffic Psychology and Behaviour, 50, 38-49. http://doi.org/10.1016/j.trf.2017.06.017

Chaloupka, F. J., Powell, L. M., \& Warner, K. E. (2019). The use of excise taxes to reduce tobacco, alcohol, and sugary beverage consumption.

Annual Review of Public Health, 40, 187-201.

http://doi.org/10.1146/annurev-publhealth-040218-043816

Coder, B., Freyer-Adam, J., Lau, K., Riedel, J., Rumpf, H. J., Meyer, C., John, U., \& Hapke, U. (2009). Reported beverage consumed and alcohol-related diseases among male hospital in patients with problem drinking. Alcohol and Alcoholism, 44(2), 216-221. http://doi.org/10.1093/alcalc/agn113

Cutright, P., \& Fernquist, R. M. (2011). Predictors of per capita alcohol consumption and gender-specific liver cirrhosis mortality rates: thirteen European countries, circa 1970-1984 and 1995-2007. Omega - Journal of Death and Dying, 62(3), 269-283. http://doi.org/10.2190/0M.62.3.d

Devaux, M., \& Sassi, F. (2015). Alcohol consumption and harmful drinking: trends and social disparities across OECD countries. OECD Health Working Papers, No. 79. France, Paris: OECD Publishing. http://doi.org/10.1787/5js1qwkz2p9s-en
Dietze, P. M., Jolley, D. J., Chikritzhs, T. N., Clemens, S., Catalano, P., \& Stockwell, T. (2009). Income inequality and alcohol attributable harm in Australia. BMC Public Health, 9, 70. http://doi.org/10.1186/1471-2458-9-70

EC. (2017). Tematický informačný prehlad európskeho semestra. Riešenie problému nerovností. Available at: https://ec.europa.eu/info/sites/info/files/file_ import/european-semester_thematic-factsheet_addressing-inequalities_sk.pdf

Elgar, F. J., Roberts, C., Parry-Langdon, N., \& Boyce, W. (2005). Income inequality and alcohol use: a multilevel analysis of drinking and drunkenness in adolescents in 34 countries. European Journal of Public Health, 15(3), 245-250. http://doi.org/10.1093/eurpub/cki093

Furceri, D., \& Ostry, J. D. (2019). Robust determinants of income inequality. Oxford Review of Economic Policy, 35(3), 490-517. http://doi.org/10.1093/oxrep/grz014

Galea, S., Ahern, J., Tracy, M., \& Vlahov, D. (2007). Neighborhood income and income distribution and the use of cigarettes, alcohol, and marijuana. American Journal of Preventive Medicine, 32(6), S195-S202. http://doi.org/10.1016/j.amepre.2007.04.003

GHO. (2019). World Health Organization databases - Global Health Observatory data repository. Available at: https://www.who.int/gho/database/en/

Gronbaek, M., Becker, U., Johansen, D., Gottschau, A., Schnohr, P., Hein, H. O., Jensen, G., \& Sorensen, T. I. A. (2000). Type of alcohol consumed and mortality from all causes, coronary heart disease, and cancer. Annals of Internal Medicine, 133(6), 411-419. http://doi.org/10.7326/0003-4819-133-6-200009190-00008

Hong, S., Han, H., \& Kim, C. S. (2020). World distribution of income for 1970-2010: dramatic reduction in world income inequality during the 2000s. Empirical Economics, 592), 765-798. http://doi.org/10.1007/s00181-019-01657-w

Hovhannisyan, A., Castillo-Ponce, R. A., \& Valdez, R. I. (2019). The determinants of income inequality: the role of education. Scientific Annals of Economics and Business, 66(4), 451-464. http://doi.org/10.2478/saeb-2019-0040

Karriker-Jaffe, K. J., Roberts, S. C. M., \& Bond, J. (2013). Income inequality, alcohol use, and alcohol-related problems. American Journal of Public Health, 103(4), 649-656. http://doi.org/10.2105/AJPH.2012.300882 
Kerr, W. C., Fillmore, K. M., \& Marvy, P. (2000). Beverage-specific alcohol consumption and cirrhosis mortality in a group of English-speaking beer-drinking countries. Addiction, 95(3), 339-346.

http://doi.org/10.1046/j.1360-0443.2000.9533394.x

Klein, W. M. P., Jacobsen, P. B., \& Helzlsouer, K. J. (2020). Alcohol and cancer risk clinical and research implications. JAMA, 323(1), 23-24,

http://doi.org/10.1001/jama.2019.19133

Kranzinger, S. (2020). The decomposition of income inequality in the EU-28. Empirica, 47(3), 643-668. http://doi.org/10.1007/s10663-019-09450-9

Lee, D. J., \& Son, J. C. (2016). Economic growth and income inequality: evidence from dynamic panel investigation. Global Economic Review, 45(4), 331-358. http://doi.org/10.1080/1226508X.2016.1181980

Liangpunsakul, S., Haber, P., \& McCaughan, G. W. (2016). Alcoholic liver disease in Asia, Europe, and North America. Gastroenterology, 150(8), 1786-1797. http://doi.org/10.1053/j.gastro.2016.02.043

Matthew, P., \& Brodersen, D. M. (2018). Income inequality and health outcomes in the United States: an empirical analysis. Social Science Journal, 55(4), 432-442. http://doi.org/10.1016/j.soscij.2018.05.001

McClure, L. A., Fernandez, C. A., Clarke, T. C., LeBlanc, W. G., Arheart, K. L., Fleming, L. E., \& Lee, D. J. (2013). Risky drinking in the older population: a comparison of Florida to the rest of the US. Addictive Behaviors, 38(4), 1894-1897, http://doi.org/10.1016/j.addbeh.2012.12.020

OECD. (2019a). Alcohol consumption among adults. Health at a Glance 2019 OECD indicators. France, Paris: OECD Publishing.

http://doi.org/10.1787/961753cf-en

OECD. (2019b). Organisation for Economic Co-operation and DevelopmentHealth Status: Life expectancy. Available at: https://stats.oecd.org/

OECD. (2020). Organisation for Economic Co-operation and Development Income inequality. Available at: https://data.oecd.org/inequality/incomeinequality.htm

O'Keefe, J. H., Bhatti, S. K., Bajwa, A., DiNicolantonio, J. J., \& Lavie, C. J. (2014). Alcohol and Cardiovascular Health: The dose makes the poison . . . or the remedy. Mayo Clinic Proceedings, 89(3), 382-393.

http://doi.org/10.1016/j.mayocp.2013.11.005

Pickett, K. E., \& Wilkinson, R. G. (2015). Income inequality and health: a causal review. Social Science \& Medicine, 128, 316-326.

http://doi.org/10.1016/j.socscimed.2014.12.031

Pruckner, N., Hinterbuchinger, B., Fellinger, M., Konig, D., Waldhoer, T., Lesch, 0. M., Gmeiner, A., Vyssoki, S., \& Vyssoki, B. (2019). Alcohol-related mortality in the WHO European region: sex-specific trends and predictions. Alcohol and Alcoholism, 54(6), 593-598. http://doi.org/10.1093/alcalc/agz063

Razvodovsky, Y. E. (2010). Beverage-specific alcohol sale and cardiovascular mortality in Russia. Journal of Environmental and Public Health, 253853. http://doi.org/10.1155/2010/253853

Rehm, J., \& Shield, K.D. (2013). Alcohol and mortality global alcohol-attributable deaths from cancer, liver cirrhosis, and injury in 2010. Alcohol Research-Current Reviews, 35(2), 174-183

Reilly, K. H., Bartley, K., Paone, D., \& Tuazon, E. (2019). Alcohol-related emergency department visits and income inequality in New York City, USA: an ecological study. Epidemiology and Health, 41, e2019041.

http://doi.org/10.4178/epih.e2019041

Roerecke, M., Vafaei, A., Hasan, O.S.M., Chrystoja, B.R., Cruz, M., Lee, R., Neuman, M.G., \& Rehm, J. (2019). Alcohol consumption and risk of liver cirrhosis: a systematic review and meta-analysis. American Journal of Gastroenterology, 114(10), 1574-1586, http://doi.org/10.14309/ajg.0000000000000340

Scherubl, H. (2019). Alcohol use and cancer risk. Deutsche Medizinische Wochenschrift, 144(19), 1354-1360, http://doi.org/10.1055/a-0928-0586
Sluik, D., Jankovic, N., Hughes, M., O'Doherty, M. G., Schottker, B., Drygas, W., Rolandsson, 0., Maennistoe, S., Ordonez-Mena, J. M., Ferrieres, J., Bamia, C., De Gaetano, G., Kiefte-De Jong, J. C., Franco, O. H., Sluijs, I., Spijkerman, A. M. W., Sans, S., Eriksson, S., Kromhout, D., ... Feskens, E. J. M. (2017). Alcoholic beverage preference and diabetes incidence across Europe: the Consortium on Health and Ageing Network of Cohorts in Europe and the United States (CHANCES) project. European Journal of Clinical Nutrition, 71(5), 659-668. http://doi.org/10.1038/ejcn.2017.4

Sornpaisarn, B., Shield, K. D., Cohen, J. E., Schwartz, R., \& Rehm, J. (2016). The association between taxation increases and changes in alcohol consumption and traffic fatalities in Thailand. Journal of Public Health, 38(4), e480-e488. http://doi.org/10.1093/pubmed/fdv163

Stigler, M. H., Neusel, E., \& Perry, C. L. (2011). School-based programs to prevent and reduce alcohol use among youth. Alcohol Research \& Health, 34(2), 157-162.

Subramanian, S. V., \& Kawachi, I. (2004). Income inequality and health: what have we learned so far? Epidemiologic Reviews, 26(1), 78-91. http://doi.org/10.1093/epirev/mxh003

Tridico, P. (2018). The determinants of income inequality in OECD countries. Cambridge Journal of Economics, 42(4), 1009-1042. http://doi.org/10.1093/cje/bex069

Vandenberg, B., Jiang, H., \& Livingston, M. (2019). Effects of changes to the taxation of beer on alcohol consumption and government revenue in Australia. International Journal of Drug Policy, 70, 1-7. http://doi.org/10.1016/j.drugpo.2019.04.012

White, H. (1980). A heteroskedasticity-consistent covariance matrix and a direct test for heteroskedasticity. Econometrica, 48(4), 817-838. http://doi.org/10.2307/1912934

White, H. (1982). Instrumental variables regression with independent observations. Econometrica, 5022), 483-499. http://doi.org/10.2307/1912639 